\title{
NEW TRENDS IN CURRENT IMPLEMENTATION OF RHEOLOGICAL TECHNOLOGIES FOR THE HUMAN BLOOD
}

\author{
Michel R. Boisseau \\ Laboratoire d'Hématologie, Université de Bordeaux II, 33076 Bordeaux, France \\ (Contribution to the Round Table Discussion at the 9th European Conference on Clinical \\ Hemorheology, Siena June 29-July 11995 )
}

During the last ten years the number of the in vivo/ ex vivo techniques in haemorheology have considerably increased and in spite of a consensus meeting held in 1986 (International Committee for Standardization in Haemorheology, ICSH,1986) little improvment can be noticed at the present time.

It appears that the number of proposed tests remains high, as many of them are obsolete and/or no longer commercially available. Cataloguing the different tests, coming out of all rheological laboratories all around the world, is extremely difficult. One can however distinguish the public techniques (viscosity, viscoelasticity, red cell aggregation, deformability), which can be obtained from manufacturers and the private or "wild" techniques only settled inside research laboratories.

Of importance is: viscosity, filtration, ektacytometry, micropipettes and in vitro flow systems (Tableau I).

TABLE I

THE METHODS IN HAEMORHEOLOGY

\section{1- Public Techniques}

\section{Viscosity}

Plasma Viscosity

Coulter Capillary Viscosimeter, Coulter Electronics

Capillary tube Viscosimeter, Schott A G

$$
\text { Whole Blood Viscosity }
$$

Contraves LS 30 (Couette type Viscosimeter)

Brookfield microcone plate Viscosimeter, model LVT (Brookfield Engineering Lab. Inc., USA)

$$
\text { - Viscoelasticity }
$$

OCR-D: oscillating capillary rheometer, PAAr, Graz (Viscoelasticity and flexibility)

- Red cell aggregation

Mini-erythrocyte aggregometer : MA1, Myrenne GmbH Erythroaggregometer Affibio, Regulex 
Laser-assisted Optical Rotational Cell Analyser (Mechatronics, Hoorn,NL)

Hanss Hemorheometer

- Deformability

St George's Filtrometer, Carrimed, UK

CTA: Cell Transit Analyser, ABX Company

Ektacytometer Technicon

Laser-assisted Optical Rotational Cell Analyser (Mechatronics, Hoorn, NL)

\section{2-Private (wild) Techniques}

\section{-Viscosity}

Cui Xizhong Cone PlateViscosimeter Tianjin

Capillary Viscosimeter, Shangai Medical University

\section{- Filtration}

Selecting-erythrocyte Rigidometer (H Kiesewetter 1983)

Filtrometer SA Evans 1990

Fitrometer AM Ehrly 1973

Filtrometer G Fisher 1993 (WH Reinhardt 1990)

Filtrometer Y Isogai 1981

CPA : Cell Passate Analyzer, Hoechst AG, Wiesbaden

\section{- Erythrodeformeter}

R J Rasia \& G Schültz 1993, A Luquita, 1994

-Micropipette

Micropipette System, Paulishke \& Nash, 1993

Micropipette System, JC Lelièvre, 1992

-In vitro - flow systems

G Nash, 1994, reproduced by M.R. Boisseau and C. Closse, 1995.

The current objectives, in haemorheology, are to be precised in order that some techniques can survive, knowing that manufacturers stop rather quickly the providing of machines...

\section{1 - Monitoring and calibration}

One particular point in rheology is the lack of mastered methods of calibration when the tests are let to be running on. In France only two attempts have been made in this way. The first is the comparison of Contraves LS in 5 laboratories after dispatching control viscous samples which showed slight differences. The second is a current research study about 5 Affibio erythroaggregometers in the same laboratories, which exhibit important differences for the same samples, thus constraining to perform an immediate adjustement of both the machinery and the soft system.... However more extensive and subsequent studies have shown that this method is stable, well defined, related to haematocrit, fibrinogen and ESR, but nevertheless giving more accurate information (1)

It must be assessed that, up to the present, no other device, system and or method are going to be calibrated or controled in any way...The concept of "normal" plasma should be rejected, as there is no normal plasma when are considered the variations of plasma factors according to the age, the state of inflammation etc... Only a strategy where the patient appears like his own control may be acceptable, before and after a treatment, for 
example, or when the measurement is plotted against another proper signal or test (see below)

Particularly important is to consider that the so called "'filtration techniques" are uncalibrated, submitted to unmastered factors and therefore obviously without any signification. Only very precise experiments performed with elaborated devices as the $\mathrm{St}$ George's filtrometer and the CTA may be taken into some account.

\section{2-Clinical applications}

At the patient bed side, tests related to the thyxotropy phenomenom are useful, for they have been studied in relevant clinical studies. Both plasma and blood viscosity, red cell aggregation and some viscoelasticity methods enter this group. The obtained results are part of the prognosis and able to evaluate the effect ot treatments (haemodilution, drugs). One particularly interest is that they indicate the final effect of blood closed factors: i.e.: haemoconcentration, high density of the plasma, dysglobulinaemia, polycythaemia, shape of cells, increased cohesion of red cell aggregates.

Among those former factors the level of the fibrinogen is particularly important and may be different along wiht the age of patients, the season and the country...(2)(3)(4)(5)(6).

The filtration techniques which are largely undetermined, do not appear useful in the literature, on the clinical point of view. A lot of changes in patients: i.e. : diabetes, sickle cell anaemia, atherosclerosis have been refered, but nothing remains in practice.

\section{3-Pharmacological studies}

Again the effects of drugs on cells has been studied using the filtration methods. These have to be carefully selected for many of them are undetermined. The more recent are better: St George's, acting upon a cell suspension or the CTA and CPA analysing the cells through a single calibrated pore. In such very cautious experiments the cells may improve their "deformability" or their "filterability" under the influence of pharmacological products.

\section{4- New trends for new devices}

The micropipette technique either for white or red cells is promising and under development, but will certainly remain a specialized research test.. The in vitro flow systems, mimicking microcirculation, are interesting : they allow studies dealing with the behaviour not only of the circulating cells, but also of the endothelial wall barrier (cultured human or animal endothelium). Recent advances in this field have shown that the properties of the microvessels are, by many aspects, shear-dependent at the level of the wall and submitted to the up-regulation of receptors and ligands recently defined. The use of inhibitors and monoclonal antibodies allow experiments to be performed, creating a better understanding of the action of rheological factors at the level of the microcirculation.

\section{5- What could be the future in haemorheolgy?}

a) Physiology \& pharmacology

The haemorheological methods will remain useful in animal experiments and in human, in order to reach a better knowledge of the microcirculation for a given function of organ. Furthermore the influence of drugs can be analyzed in such techniques, using blood, plasma and cells.

\section{b) At the patient bedside}

When an interest in rheology is to be found out for patients, only the thyxotropic related methods are able to provide this. In pre-operative periods, before and after haemodilution, haemorheolgy is useful, as well as in neonates. 
One can also investigate the importance of rheological data in performing the comparison with other biological or functional parameters. For example red cell aggregation correlated with TC-PO2 investigation in ischemic patients (7). This latter result appears extremely interesting and incentive for a future development of haemorheologiclal investigation at the patients bed side.

\section{REFERENCES}

1- Potron $\mathrm{G}$ et al. Approach to eryhtrocyte aggregation through erythrocyte sedimentaion rate: application of a stastitical model in pathology. Nouv Rev Fr Haematol, 1994, 36, $242-247$

2- Ernst E. Plasma fibrinogen, an independent cardiovascular risk factor. J of Int Med, $1990,227,365-372$

3- Koenig W et al. Association between plasma viscosity and blood pressure. Results from the MONICA-project Augsburg. Am J Hypertens, 1991, 4, 529-536

4- Lowe G D O et al. Relationship of plasma viscosity, coagulation and fibrinolysis to coronary risk factor and angina. Thromb \& Haemost, 1991, 65, 339-343

5- Avellone A et al. Coagulation, fibrinolysis and haemorheology in premenopausal obese women with different body fat distribution. Thromb Res, 1994, 75, 223-231

6- Hager H et al. Fibrinogen and aging. Aging Clin Exp Res, 1994, 6 133-138

7- Dupuis-Fons C et al. Relationships between blood rheology and transcutaneaous oxygen pressure in peripheral oclusive arterial disease. Clin Hemorheol, 1995, 15, 191 200 . 